\title{
Basement membrane and apocrine epithelial antigens in differential diagnosis between tubular carcinoma and sclerosing adenosis of the breast
}

\author{
PETER EKBLOM, MARKKU MIETTINEN, LISBETH FORSMAN, LEIF C ANDERSSON \\ From the Department of Pathology, University of Helsinki, Haartmaninkatu 3, SF-00290 Helsinki 29, \\ Finland
}

SUMMARY The distributions of defined basement membrane proteins in nine pure tubular carcinomas, 10 cases of sclerosing adenosis, and 15 ductal adenocarcinomas were compared. Sections of formalin fixed, paraffin embedded specimens were pretreated with pepsin and then immunostained for laminin, type IV collagen, and basement membrane proteoglycan, components specific for basement membranes. In sclerosing adenosis the tubules were surrounded by a continuous intact basement membrane composed of laminin, type IV collagen, and basement membrane proteoglycan, while the epithelium in the tubular carcinomas was negative for these proteins. The tumours were also analysed for the distribution of the apocrine epithelial antigen (AEA). In contrast to the benign lesions the tubular carcinomas expressed the AEA in a distinct non-polar fashion throughout the cell surface. In normal ducts and in adenosis the AEA was confined exclusively to the luminal surface. These studies suggest that there is a disturbance of cell polarity in tubular carcinomas. It is concluded that a combined analysis of basement membrane proteins and luminal surface antigens is a reliable and convenient way to differentiate between tubular carcinoma and sclerosing adenosis of the breast.

The well differentiated tubular carcinoma is a rare type of breast carcinoma. ${ }^{2}$ It is often difficult to distinguish this carcinoma from sclerosing adenosis, a benign pseudoinfiltrative lesion. ${ }^{3}$ Although both conditions have a good prognosis, their treatment differs and the correct diagnosis is therefore important $^{4-7}$ Both electron microscopy and ordinary histology of material stained with periodic acid Schiff have suggested that the tubules in tubular carcinoma, in contrast to the tubules in sclerosing adenosis, lack a basement membrane..$^{4-11}$

Recently, proteins specific for basement membranes have been identified and characterised..$^{12-15}$ These proteins can easily be detected also from old, formalin fixed and paraffin embedded material using specific antibodies if sections are pretreated with enzymes. ${ }^{16}$ We have therefore used these methods to find out whether antibodies against basement membrane components can be used in the differential diagnosis between tubular carcinoma and sclerosing adenosis. The expression of laminin in frozen sections of breast tumours has been studied

Accepted for publication 28 September 1983 recently, but data on tubular carcinomas have not been reported. ${ }^{17}$ The tumours were also analysed for the distribution of the apocrine epithelial antigen, which in normal cells is a marker for the luminal surface.

\section{Material and methods}

Five cases of pure, well differentiated tubular carcinoma, 10 cases of sclerosing adenosis, and 15 cases of ductal adenocarcinoma were taken from the files of the Department of Pathology, University of Helsinki. Four tubular carcinomas were obtained from the Department of Pathology, Jorvi Hospital, Espoo, Finland as a gift from Dr Seppo Partanen. All samples had been stored at room temperature for at least one year after formalin fixation.

For the detection of basement membrane proteins, sections were deparaffinised, treated with a $0.4 \%$ solution of pepsin in $0.01 \mathrm{NHCl}$ for $2 \mathrm{~h}$ at $37^{\circ} \mathrm{C},{ }^{161 \times 19}$ washed, and then reacted with rabbit antibodies against mouse laminin, type IV collagen, and basement membrane proteoglycan. ${ }^{13-15}$ The antibodies were a kind gift from JM Foidart, Uni- 
versity of Liege, Belgium. The bound antibodies were then detected by indirect immunofluorescence or by immunoperoxidase staining procedures. Fluorescein conjugated sheep antirabbit IgG was obtained from Wellcome Laboratories, Beckenham, UK. The indirect immunofluorescence procedures were performed as described previously. ${ }^{2021}$

For immunoperoxidase stainings, the enzyme treated sections were first reacted with $0.2 \% \quad \mathrm{H}_{2} \mathrm{O}_{2}$ before applying the antibodies. The sections were then treated either with a rabbit antiperoxidase antiserum coupled to peroxidase (PAP, Dakopatts AG, Copenhagen, Denmark, diluted 1/100 in phosphate buffered saline (PBS) containing 3\% swine serum) or with a biotinylated antirabbit immunoglobulin antiserum (dilution 1/500), avidin (dilution 1/1000), and biotinylated horseradish peroxidase complex (Vector Laboratories, Burlingame, California). The peroxidase reactions were developed by $0.1 \% \mathrm{H}_{2} \mathrm{O}_{2}$ and $0.05 \% \quad 3,3$ diamino-benzidine tetrahydrochloride (Fluka AG, Buchs, Switzerland) for $10 \mathrm{~min}$ in the dark. Some slides were then counterstained for nuclei with Meyer's haematoxylin. Similar results were obtained with all staining methods used. No reaction with the antibodies was seen unless the enzyme pretreatment ${ }^{16}$ was performed. Results of control stainings with preimmune serum were negative. Photographs were taken from slides stained by the immunoperoxidase procedures.

Rabbit antiserum against milk fat globule glycoprotein, which we call apocrine epithelial antigen (AEA), was prepared in the following way. Human milk fat globules were isolated by centrifugation and the membranes separated from the butter oil by repeated extractions with $\mathrm{PBS}$ at $50^{\circ} \mathrm{C}$. The membrane preparation was solubilised in $1 \%$ Triton $\mathrm{X}-100$ in PBS and the glycoproteins were isolated by passage over a concanavalin A-sepharose column. The retained glycoproteins were eluated by alpha-methyl-pyrano-mannopyranoside. To obtain a more distinct reactivity with the formalin fixed preparations the isolated glycoproteins were treated with $4 \%$ formaldehyde in PBS and dialysed overnight against PBS. Rabbits were repeatedly immunised with $400-500 \mathrm{mg}$ of formalin treated glycoproteins emulsified in Freunds adjuvant, and the resulting antisera were absorbed before use with erythrocytes and normal blood leucocytes from buffy coats of blood units of $400 \mathrm{ml}$. The anti-AEA antiserum is specific for apocrine epithelium and reacts well as a $1 / 20$ dilution also in formalin fixed samples. ${ }^{22}$ The detailed characterisation of the anti-AEA antiserum will be reported elsewhere (Forsman et al, in preparation).

The AEA was detected in sections by indirect immunofluorescence. Since the antibodies are directed against formalin treated AEA no enzyme pretreatment was necessary. The deparaffinised slides were reacted with a $1 / 20$ dilution of the rabbit antibody against AEA, washed, and reacted with fluorescein-isothiocyanate conjugated swine antirabbit IgG (1/50, Dakopatts AG, Copenhagen, Denmark), washed again, and processed for immunofluorescence microscopy.

All samples were also stained with periodic acid Schiff and Weigerts's van Gieson.

\section{Results}

In all cases of sclerosing adenosis the tubular structures were positive for laminin (Fig. 1), type IV collagen, and basement membrane proteoglycan (Fig. 2 ). The positive reaction was seen as a continuous line on the basal side of the basal layer of the ducts. Several basal cells also showed intracellular positivity (Fig. 3). This staining pattern was similar to that seen in normal ducts (Fig. 4). Vessel walls were also positive for the proteins.

In tubular carcinomas no reaction around the tubules of the carcinoma cells was seen for either laminin, type IV collagen, or basement membrane proteoglycan (Figs. 5 and 6). The vascular endothelium found within the tumour was invariably positive for these proteins, and this shows that the negative findings were not due to any technical failures in the staining procedures. The normal ducts seen in the same specimen were also positive for the basement membrane proteins. In some tubules parts of the growing tubule were surrounded by a continuous basement membrane, while other parts contained cells which expressed the proteins in a punctate pattern. This pattern was, however, a rare finding. Staining results in the tubular carcinomas were in all respects similar with antibodies against laminin, type IV collagen, and basement membrane proteoglycan. Results were also negative in the tubular carcinomas when high concentrations of antibodies (antilaminin 1/10) were applied. Thus, although the lack of reactivity with the antibodies can be due to small amounts of the proteins, they were not detectable with any concentrations of the antibodies used.

Indirect immunofluorescence for the AEA showed different patterns in the tubular carcinomas and the adenosis. In benign lesions the AEA was found exclusively at the luminal surface of the ductal epithelium (Fig. 7). In contrast, the entire membrane of the cells in the malignant epithelium stained for AEA (Fig. 8).

The expression of laminin and other basement membrane proteins in ductal carcinomas was slightly different from that in tubular carcinomas. In non- 




Fig. 1 Sclerosing adenosis stained for laminin. (PAP, no counterstain). $A$ positive reaction is seen extracellularly at the basal surface. No discontinuities are detected.



Fig. 2 Sclerosing adenosis stained for basement membrane proteoglycan. (PAP, no counterstain). Typical slightly irregular, ragged tubules are seen. The basement membrane area is uniformly decorated with the antibody. 




Fig. 3 Higher magnification of tubular structures in sclerosing adenosis. Antilaminin antibodies. Note the strong continuous linear staining both in the tubules and in the surrounding vessel walls. (PAP, no counterstain). invasive edges which represented intraductal carcinomas laminin was seen in the periphery of the epithelial sheets in the basement membrane area in a continuous fashion. In invasive areas frequent discontinuities in the laminin expression were seen, and many areas were completely lacking laminin extracellularly. Some of the infiltrating cells expressed laminin intracellularly. Results for the ductal carcinomas were the same in frozen sections and in enzyme treated sections made from samples fixed in formalin. The results for the ductal carcinomas confirm the findings by Albrechtsen et $\mathrm{al}^{17}$ and Siegal et al..$^{23}$ As in the tubular carcinomas, the entire surface of epithelium in the ductal carcinomas was positive for the AEA (not illustrated).

\section{Discussion}

Although the prognosis of tubular carcinoma is good, the condition should be differentiated from

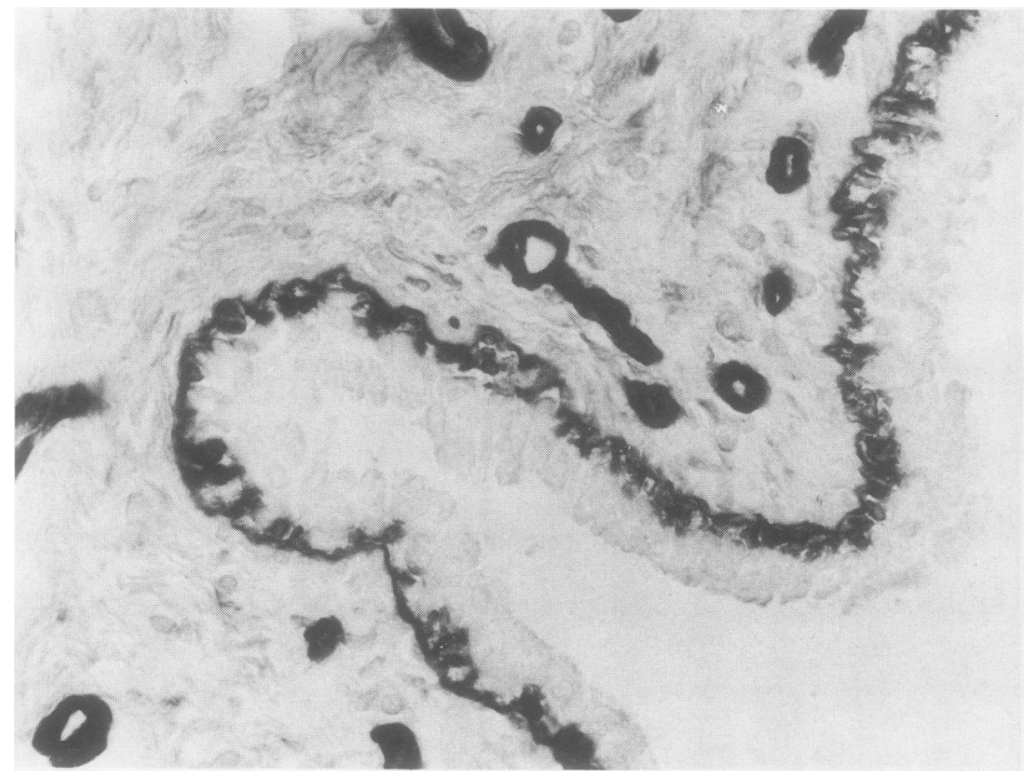

Fig. 4 A normal breast duct showing continuous linear staining of basement membrane.

Antilaminin antibodies. Note also staining within basal cells and in vessel walls (PAP, no counterstain). 


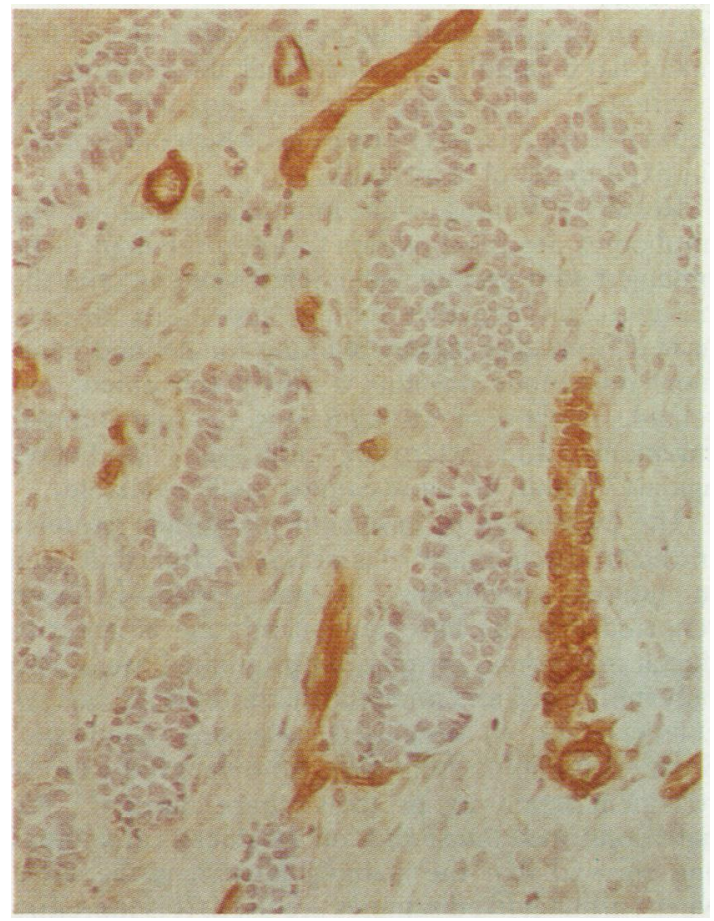

Fig. 5 Tubular carcinoma stained for laminin.

(biotinyl-avidin procedure, with counterstain). Note complete lack of reaction in the carcinoma tubules as compared with the vessel walls. The counterstain showed the slightly angulated tubules, which are in places composed of polarly orientated cells.

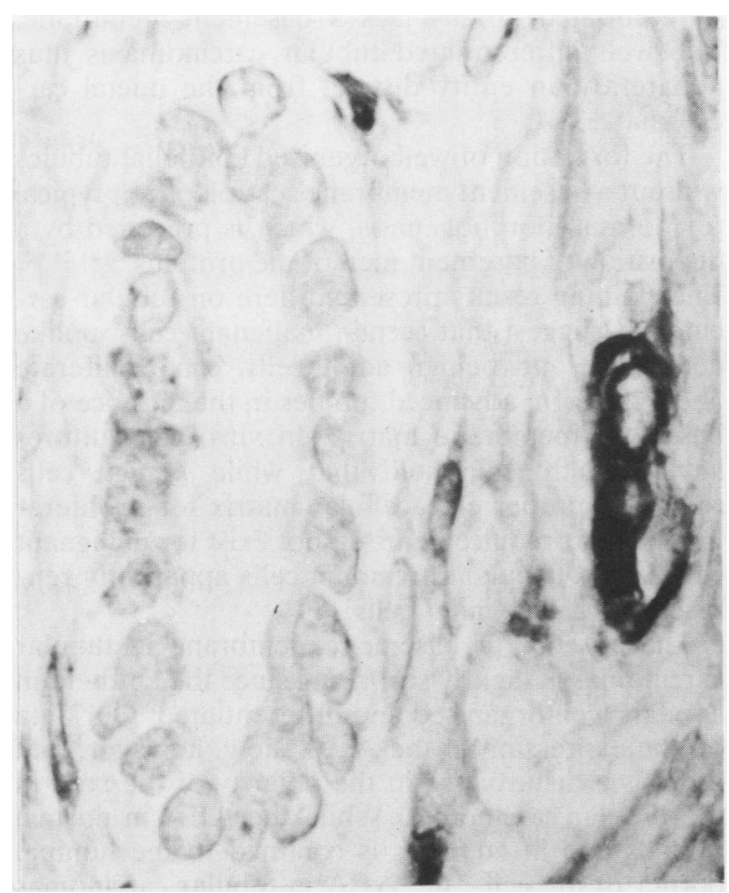

Fig. 6 Tubular carcinoma stained for basement membrane proteoglycan. (biotinyl-avidin procedure, with counterstain). Only the vessel walls are positive. 


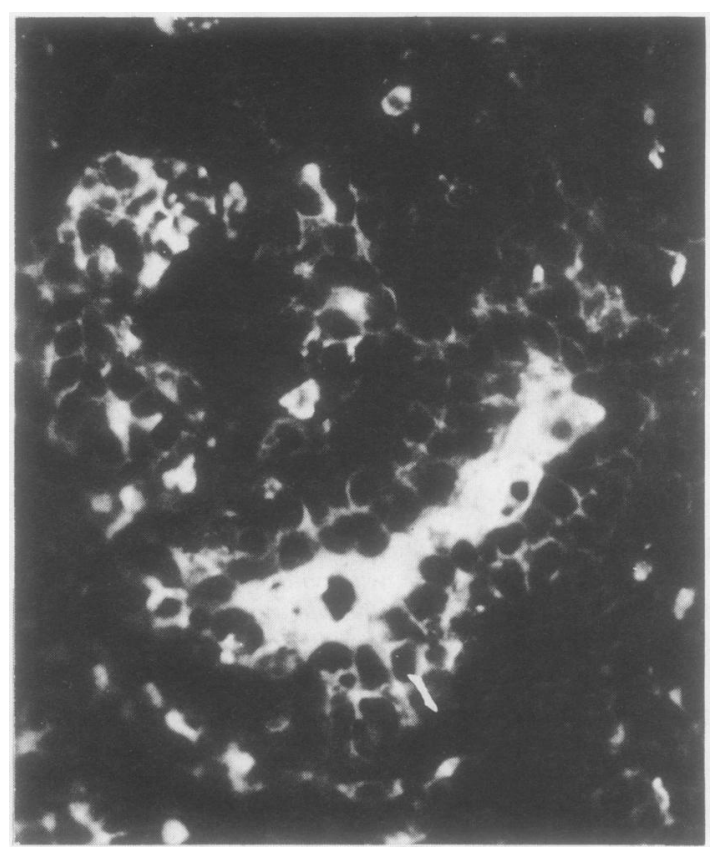

Fig. 8 Tubular carcinoma stained for apocrine epithelial antigens. Bright fluorescence is detected in the lumen, but there is also strong staining throughout the cell surface of all cells.

sclerosing adenosis. Tubular carcinoma may be a histological marker for a subpopulation of patients with other types of mammary carcinomas. ${ }^{1-624}$ Recent clinicopathological studies suggest that simple excision of tubular carcinomas is inadequate as treatment. ${ }^{7}$ Because of the uniform shape of the ducts in the tubular carcinomas the disease is sometimes difficult to distinguish from sclerosing adenosis purely on morphological grounds. The clearest abnormality reported in tubular carcinomas seems to be the lack of an ultrastructurally detectable basement membrane. ${ }^{8-10}$ It was recently suggested that the presence or absence of basement membrane can be evaluated at the light microscopy level using ordinary periodic acid Schiff staining. "1 Light microscopy offers several advantages over electron microscopy. Above all, it is possible to examine the whole tissue specimen and to correlate staining results with histopathology. Since periodic acid Schiff staining is not specific for basement membranes, we used antibodies that react exclusively with defined components of basement membranes. We found that the tubules in the well differentiated (tubular) carcinomas totally lack the basement membrane proteins studied. In contrast, the tubules in sclerosing adenosis expressed all these basement membrane proteins. As shown in the present study, the stainings can easily be performed from old formalin fixed samples provided that the sections are pretreated with pepsin. It is thus possible to do a retrospective analysis of cases for which only formalin fixed material is available.

Results obtained with immunostaining of the antibodies are much easier to interpret than those obtained with periodic acid Schiff staining, and the positive and negative tubules are easily distinguished from each other. Staining for defined basement membrane proteins is thus a convenient and reliable method of distinguishing between tubular carcinoma and sclerosing adenosis. Antibodies against laminin are now commercially available.

The expression of basement membrane proteins in ductal carcinomas ${ }^{17}{ }^{23}$ is different from that seen in tubular carcinomas. It has previously been reported that the basement membrane is intact in ductal carcinomas in more differentiated areas, and only infiltrating and poorly differentiated ductal carcinomas lack an organised basement membrane. Some of the infiltrating cells, however, still express basement membrane proteins intracellularly. ${ }^{1723} \mathrm{We}$ have confirmed the studies on the ductal carcinomas and showed that the staining pattern is the same when formalin fixed samples are used. It is therefore notable that the tubular carcinomas, although well differentiated, totally lack a basement membrane. The well differentiated tubular carcinoma is thus apparently an entity distinct from the ductal carcinoma.

The formation of well organised epithelial tubules without a basement membrane scaffold is not typical for normal morphogenesis, which is preceded by a deposition of basement membrane proteins. ${ }^{202125-27}$ The staining results presented here on tubular carcinomas suggest that certain malignant cells, unlike embryonic and benign adult cells, can proliferate and even form advanced tubules in the absence of a basement membrane matrix. In vitro cell cultures have already suggested that while benign cells require a proper extracellular matrix for proliferation, similar requirements do not exist for malignant cells. ${ }^{28-31}$ Tubular carcinoma cells apparently represent such malignant cells.

The absence of basement membrane in tubular carcinomas is slightly surprising since the epithelium appears well organised and differentiated. Our data on the expression of the AEA show, however, that there is a disturbance in the polarity of the cells in the tubular carcinomas. While the AEA in normal tubules and in adenosis is confined to the luminal border of the cells, the AEA in tubular carcinomas is expressed in a distinctly non-polar fashion throughout the cell surface. It is possible that the lack of a basement membrane leads to a loss of cell 
polarity. In vitro studies have clearly shown the importance of the basolateral surface in the maintenance of cell shape and differentiation of mammary epithelial cells..$^{32-33}$ Regardless of the mechanisms behind the loss of cell polarity in the tubular carcinomas, it is evident that a combined analysis of basement membrane proteins and AEA offers an aid in the differential diagnosis between tubular carcinomas and adenosis.

This work was supported by grants from Finska Läkaresällskapet and the Sigrid Juselius Foundation.

\section{References}

' Carstens PHB, Huvos AG, Foote FV Jr, Ashikari R. Tubular carcinoma of the breast: A clinicopathologic study of 35 cases. Am J Clin Pathol 1972;58:231-8.

2 Taylor HB, Norris HJ. Well-differentiated carcinoma of the breast. Cancer 1972;25:231-8.

${ }^{3}$ Fenoglio C, Lattes R. Sclerosing papillary proliferation in the female breast: a benign lesion often mistaken for carcinoma. Cancer 1974;33:691-700.

${ }^{4}$ Tobon H, Salazar $\mathrm{H}$. Tubular carcinoma of the breast: clinical, histological and ultrastructural observations. Arch Pathol 1977;101:310-6.

${ }^{5}$ Nemoto T, Vana J, Bedwani RM. Management and survival of female breast cancer. Results of a national survey by the American College of Surgeons. Cancer 1080;45:2917-24.

${ }^{6}$ Linell F, Ljungberg O, Andersson I. Breast carcinoma. Aspects of early stages, progression, and related problems. Acta Pathol Microbiol Scand 1980; sect A, suppl 272.

' Deos PH, Usaf MC, Norris HJ. Well differentiated (tubular) carcinoma of the breast. A clinicopathological study of 145 pure and mixed cases. Am J Clin Pathol 1982;78:1-7.

${ }^{8}$ Erlandson RA, Carstens PHB. Ultrastructure of tubular carcinoma of the breast. Cancer 1972;29:987-95.

' Harris M, Ahmed A. The ultrastructure of tubular carcinoma of the breast $J$ Pathol 1977;123:79-83.

${ }^{10}$ Jao W, Recant W, Sverlow MA. Comparative ultrastructure of tubular carcinoma and sclerosing adenosis of the breast Cancer 1977; 40: 1726-34.

"Flotte TJ, Bell DA, Greco MA. Tubular carcinoma and sclerosing adenosis - the use of basal lamina as a differential feature. Am J Surg Pathol 1980;4:45-7.

12 Timpl R, Rohde H, Robey PG, Rennard SI, Foidart JM, Martin GR. Laminin-a glycoprotein from basement membranes. $J$ Biol Chem 1979;254:9933-7.

${ }^{13}$ Foidart JM, Bere EW, Yaar M, et al. Distribution and immunoelectron microscopic localization of laminin, a noncollagenous basement membrane glycoprotein. Lab Invest 1980;42:336-42.

${ }^{14}$ Hassell JR, Robey PG, Barrach HJ, Wilcek J, Rennard SI, Martin GR. Isolation of a heparan-sulfate containing proteoglycan from basement membrane. Proc Natl Acad Sci USA 1980;77:4494-8.

15 Timpl R, Martin GR. Basement membrane components. In: Furthmayr H, ed. Immunochemistry of the extracellular matrix. Florida, Boca Raton, 1982:119-50.

${ }^{16}$ Ekblom P, Miettinen M, Rapola J, Foidart JM. Demonstration of laminin, a basement membrane glycoprotein, in routinely processed formalin-fixed human tissues. Histochemistry 1982;75:301-7.
17 Albrechtsen R, Nielsen M, Wewer U, Engvall E, Ruoslahti E. Basement membrane changes in breast cancer detected by immunochemical staining for laminin. Cancer Res 1981;41:5076-81.

${ }^{18}$ Brozman M. Immunohistochemical analysis of formaldehyde and trypsin- or pepsin-treated material. Acta Histochem 1978;63:251-60.

${ }^{19}$ Burns J, Dixon AJ, Woods JC. Immunoperoxidase localization of fibronectin in glomeruli of formalin-fixed paraffin processed renal tissues. Histochemistry 1980;61:13-8.

${ }^{20}$ Ekblom P. Formation of basement membranes in the embryonic kidney. An immunohistological study. J Cell Biol 1981;91:110.

${ }^{21}$ Ekblom P, Alitalo K, Vaheri A, Timpl R, Saxén L. Induction of a basement membrane glycoprotein in embryonic kidney: possible role of laminin in morphogenesis. Proc Natl Acad Sci USA 1980;77:485-9.

${ }^{22}$ Kariniemi A-L, Forsman L, Wahlström T, Vesterinen E, Andersson LC. Expression of differentiation antigens in mammary and extramammary Paget's disease. $\mathrm{Br} \mathrm{J}$ Dermatol (in press).

${ }^{23}$ Siegal GP, Barsky SH, Terranova VP, Liotta LA. Stages of neoplastic transformation as monitored by dissolution of basement membrane components. Invasion Metastasis 1981;1:54-70.

${ }^{24}$ Lagios MD, Rose MR, Margolin FR. Tubular carcinoma of the breast. Association with multicentricity, bilaterality, and familial history of mammary carcinoma. Am J Clin Pathol 1980;73:25-30.

${ }^{25}$ Liotta LA, Wicha MS, Foidart JM, Rennard SI, Garbisa S, Kidwell WR. Hormonal requirements for basement membrane collagen deposition by cultured rat mammary epithelium. Lab Invest 1979;41:511-8.

${ }^{26}$ Vracko R. Basal lamina scaffold. Anatomy and significance for maintenance of orderly tissue architecture. Am J Pathol 1974;77:314-38.

${ }^{27}$ Warburton MJ, Mitchell D, Ormerod EJ, Rudland P. Distribution of myoepithelial cells and basement membrane proteins in the resting, pregnant, lactating, and involuting rat mammary gland. J Histochem Cytochem 1982;30:667-76.

${ }^{28}$ Ash BB, Kamat BR, Burstein NA. Interactions of normal, dysplastic, and malignant mammary epithelial cells with fibronectin in vivo and in vitro. Cancer Res 1981;41:2115-25.

${ }^{29}$ Kidwell WR, Wicha MS, Salomon D, Liotta LA. Differential recognition of basement membrane collagen by normal and neoplastic mamary cells. In: Liotta L, ed. Cell biology of breast cancer. New York: Academic Press, 1981:17-32.

${ }^{30}$ Liotta LA, Vembu D, Kleinman HK, Martin GR, Boone G. Collagen required for proliferation of cultured connective tissue cells but not their transformed counterparts. Nature 1978;272:622-4.

${ }^{31}$ Wicha MS, Liotta LA, Garbisa S, Kidwell WR. Basement membrane collagen requirements for attachment and growth of mammary epithelium. Exp Cell Res 1979;124: 181-90.

${ }^{32}$ Emerman JT, Enami J, Pitelka DR, Nandi S. Hormonal effects on intracellular and secreted casein in cultures of mouse mammary epithelial cells on floating collagen membranes. Proc Natl Acad Sci USA 1977;74:4466-70.

${ }^{33}$ Shannon JM, Pitelka DR. The influence of cell shape on the induction of functional differentiation in mouse mammary cells. In Vitro 1981;17:1016-28.

Requests for reprints to: Dr Peter Ekblom, Department of Pathology, University of Helsinki, Haartmaninkatu 3, SF-00290 Helsinki 29, Finland. 